\title{
Mapping of genomic regions associated with net form of net blotch resistance in barley
}

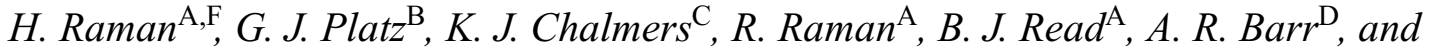 \\ D. B. Moody ${ }^{\mathrm{E}}$
}

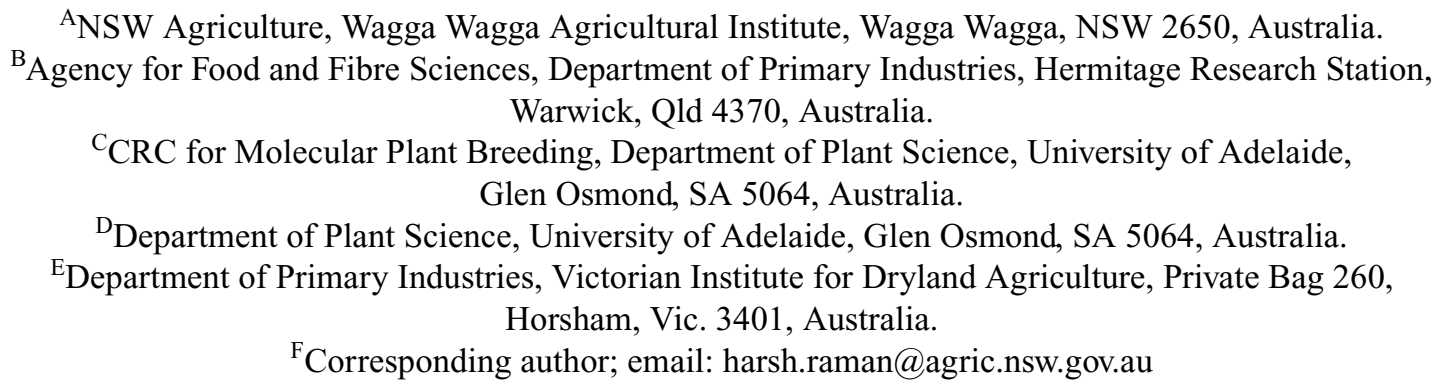

\begin{abstract}
Quantitative trait loci (QTLs) associated with resistance to net blotch and their chromosomal locations were determined from analyses of doubled haploid progeny of Alexis/Sloop, Arapiles/Franklin, Sloop/Halcyon, and recombinant inbred lines of Sloop-sib/Alexis. Five QTLs on chromosomes $2 \mathrm{H}, 3 \mathrm{H}$, and $4 \mathrm{H}$ were found to be associated with seedling resistance to the net form of net blotch. In Arapiles/Franklin and Alexis/Sloop populations, 4 significant QTLs explaining $9-17 \%$ of the variation in net blotch resistance were detected on $2 \mathrm{H}$ and $3 \mathrm{H}$. A major locus, QRpts $4 L$ accounting for $64 \%$ of the variation in infection type, was detected on $4 \mathrm{H}$ in the Sloop/Halcyon population. In Sloop/Halcyon, 2 microsatellite markers, EBmac0906 and GMS089, and AFLP marker P13/M50108 , co-segregated and detected maximum variability for net blotch resistance as revealed by bootstrap analysis. EBmac0906 and Bmac0181 were validated in $\mathrm{F}_{2}$ progeny of an Ant29/Halcyon population and reliably predicted phenotypes of $93 \%$ of lines resistant and susceptible to net blotch. These markers may be used within breeding programs to select alleles favourable for net blotch resistance derived from Halcyon.
\end{abstract}

Additional keywords: seedling resistance, Pyrenophora teres f. teres, QTL, validation.

\begin{abstract}
Introduction
Net blotch, caused by the fungus Drechslera teres (Sacc.) Shoem. f. teres Smedeg. (Teleomorph: Pyrenophora teres Drechs. f. teres Smedeg), is one of the most significant foliar diseases of barley throughout the world (Shipton et al. 1973). The disease exists as two forms, the spot form caused by $P$. teres f. maculata and the net form caused by $P$. teres $\mathrm{f}$. teres, and these can be differentiated on the basis of leaf symptoms (Smedegaard-Petersen 1971). Although the common name often embraces both forms of the disease, in this paper it refers exclusively to the net form and is abbreviated as NFNB. This disease causes a net type lesion, which is characterised by elongate, dark brown blotches often with a net-like pattern. In susceptible seedlings, production of toxins by the pathogen leads to rapid and extensive leaf death. The disease can cause yield losses in excess of $50 \%$ and also considerably reduce grain quality
\end{abstract}

(Tekauz 1990; Steffenson et al. 1996; Poulsen et al. 1999). Identification of sources of resistance to NFNB and an understanding of their genetics are very important in developing resistant varieties (Jalli and Robinson 2000). NFNB resistance is due to either one or several genes and is dependent upon the source of resistance, plant development stage (seedling or adult), and the pathotype used for testing (Mode and Schaller 1958; Wilcoxson et al. 1992; Graner et al. 1996; Steffenson et al. 1996). At adult plant stages, 712 quantitative trait loci (QTLs) associated with net blotch resistance have been identified, located on all barley chromosomes except 5H (Steffenson et al. 1996; Richter et al. 1998).

Most Australian barley cultivars are susceptible or moderately susceptible to one or more pathotypes of the disease (G. J. Platz, unpublished data). However, useful variability for resistance is present in world barley 
germplasm (Tekauz and Buchannon 1977) and has been exploited to introduce useful genes from different resistant sources into barley breeding programs. The cultivars Alexis, Franklin, and Halcyon are being used to introgress desirable genes for disease resistance, malting quality, and growth habit into adapted Australian barley cultivars. Screening of parental lines of populations within the Australian National Barley Molecular Marker Program (NBMMP) with a range of Australian pathotypes of NFNB identified differences in susceptibilities at the seedling stage between Alexis and Sloop, Arapiles and Franklin, and Sloop and Halcyon.

Selection for net blotch resistance in breeding programs has been based on host reaction at the seedling and/or adult plant stage. Molecular markers are recognised as powerful tools for indirect selection and would enhance the efficiency and accuracy of screening for NFNB resistance. Furthermore, quantitative analysis has proven useful for locating genes controlling complex traits and provides a more accurate estimation of gene location than qualitative analysis because of its lower sensitivity to even modest numbers of phenotypic mis-scores (Wright et al. 1998). The role and location of QTLs controlling resistance to NFNB in Sloop, Arapiles, Alexis, Franklin, and Halcyon were unknown. Identification of molecular markers associated with major gene loci and QTLs conferring NFNB resistance is imperative for marker assisted selection (MAS) and to facilitate combination of various QTLs to develop higher levels of net blotch resistance. This paper reports the mapping of QTLs for net blotch resistance in 4 populations derived from Alexis/Sloop, Sloop-sib/Alexis, Arapiles/ Franklin, and Sloop/Halcyon as part of the NBMMP.

\section{Materials and methods}

\section{Mapping populations and genetic maps}

Three doubled haploid (DH) mapping populations derived from Alexis/ Sloop, Arapiles/Franklin, and Sloop/Halcyon and one population of $\mathrm{F}_{4^{-}}$ derived recombinant inbred lines (RILs) from Sloop-sib/Alexis were generated by the NBMMP. Full linkage maps based upon amplified fragment length polymorphism (AFLP), restriction fragment length polymorphism (RFLP), microsatellite, and single nucleotide polymorphism (SNP) markers were constructed (Barr et al. 2003, this issue; Read et al. 2003, this issue; D. B. Moody et al. unpublished data). These molecular maps were utilised to define the location of QTLs and the linked markers associated with NFNB resistance at the seedling stage.

\section{Pathogen isolates}

Screening of parental lines in the NBMMP with a selection of net blotch isolates (Gupta et al. 2003, this issue) indicated that isolate NB34 differentiated between Arapiles and Franklin and Alexis and Sloop, whereas NB50 gave superior separation between Halcyon and Sloop. Cultures of NB34 and NB50, preserved in the form of infected dry leaf at $-70^{\circ} \mathrm{C}$, were retrieved from storage and heat-shocked at $45^{\circ} \mathrm{C}$ for $3 \mathrm{~min}$. Infected leaf pieces were maintained in a moist dish for 2-3 days at $19^{\circ} \mathrm{C}$ with $12 \mathrm{~h}$ of light $(12 \mathrm{~L})$ supplied by 2 blue-black and one cool white fluorescent tube from a distance of $20 \mathrm{~cm}$. Conidia were then picked from the leaf with a sterile needle, cultured on V8 agar, and incubated in the dark at $25^{\circ} \mathrm{C}$ for 5 days. Plugs were cut from the edges of colonies, placed on peanut oatmeal agar medium (Speakman and Pommer 1986), and incubated for 9 days at $19^{\circ} \mathrm{C}$ and $12 \mathrm{~L}$ as above.

\section{Screening for net blotch resistance}

Two replications of 5-7 seeds of each line were sown at 3 sites around the circumference of a 10-cm maxi pot (Garden City Plastics) containing a peat/loam/vermiculite medium $(1: 2: 1$ by vol.) and raised in a glasshouse at $15 / 25^{\circ} \mathrm{C}$ and $10-12 \mathrm{~h}$ photoperiod. Plants were fertilised weekly after emergence, with single strength Aquasol (Hortico Australia) to avoid any nutrient deficiency. After about 14 days, when seedlings were at the 2-leaf stage, they were inoculated with an aqueous suspension containing 15000 conidia of the target isolate/ $\mathrm{mL}$. Pots were arranged shoulder to shoulder and $200 \mathrm{~mL}$ of suspension was applied per $\mathrm{m}^{2}$ of occupied bench space using an airless spray gun (Krebs Inc.). Inoculated seedlings were incubated in a fogging chamber at $19^{\circ} \mathrm{C}$ under $14-\mathrm{h}$ dark followed by 10 -h light. Seedlings were then returned to the glasshouse and infection response (IR) on the second leaf recorded 8 days later using the scale of Tekauz (1985). IRs used for analysis were means of the 2 replicates.

\section{Statistical analyses}

Chi-square analyses were performed to test the goodness-of-fit of the observed over the expected genetic ratios for net blotch infection response.

\section{QTL analysis}

The 4 fully constructed linkage maps of the above populations were utilised for QTL analyses. Marker and quantitative phenotypic data from infection response (1-10) were evaluated using MapManager QTX (MMQTX) version 17b (Manly et al. 2001). Initially, a singlepoint regression analysis was performed using the 'QTL Marker Regression' with a threshold of $P=0.001$. The significant associations between markers and infection response data were tested using likelihood ratio statistics (LRS, Haley and Knott 1992). As a second step, simple interval mapping (SIM) analysis was performed to find evidence of QTLs by MapManager and/or QTL Cartographer (Wang et al. 2003) and QGENE (Nelson 1997). Significance thresholds for the test statistics were estimated by 1000 permutations at a significance level of $P=0.001$ (Doerge and Churchill 1996) by following the algorithm implemented in MMQTX. QTL effects were considered significant either when they exceeded a $\log _{10}$ of the odds ratio (LOD) score of 3.0 or the calculated statistic value by permutation tests (significant at $P=0.05$, highly significant at $P=0.001$ ). The conventional base LOD score was converted to LRS by multiplying it by 4.60 for comparisons as described by Manly et al. (2001). QTLs were declared at the genomic position of the test statistic's peak for the main effect and/or their interaction with environment. Bootstrap analysis was performed to estimate a confidence interval and to record the position of the maximum LRS (Visscher et al. 1996). In a third approach, composite interval mapping (CIM) was performed to explore the effect of QTL combinations and to separate additional environmental effects that may have reduced the significance of estimated marker trait association (Zeng 1994). To reveal interactions or epistatic effects, 2-locus analysis was performed using $P=10 \mathrm{e}^{-6}$ and interactions were tested for significance with an additive model using permutation tests in MMQTX.

\section{Nomenclature of QTLs}

A 'QRpt' indicates a QTL/genomic region for resistance to P. teres $\mathrm{f}$. teres. This is followed by ' $\mathrm{s}$ ' to indicate a seedling and followed by the barley chromosome arm onto which the QTL/genomic region was mapped. 
Validation of microsatellite markers linked with NFNB resistance in Halcyon

An $\mathrm{F}_{2}$ population comprising 81 plants derived from Ant29/Halcyon was screened for resistance to NFNB as described above. Healthy leaf samples from these were used for validation of 4 microsatellite markers (EBmac0906, Bmac0310, Bmag0353, Bmac0181), which mapped within $10 \mathrm{cM}$ of the locus conferring NFNB resistance in Sloop/ Halcyon. These markers have been reported to map closely in barley populations derived from Lina/Canada Park, WB229/Yambla, and Dayton/Harlan Hybrid (Ramsay et al. 2000; Raman et al. 2002, 2003 , this issue). Deoxyribonucleic acid was extracted in $2 \mathrm{~mL}$ Eppendorf tubes as described previously (Raman and Read 2000). Microsatellite analyses were performed following PCR conditions as described by Ramsay et al. (2000).

\section{Results}

\section{Seedling resistance to net form of net blotch}

The IRs of all parents were consistent across replicates, although Arapiles showed a 2-unit difference (Table 1). Although most lines gave IRs similar to those reported by Gupta et al. (2003), Alexis was higher (6.5 v. 4.5) and Arapiles lower $(8 v .10)$ than in the initial parent screening.

After inoculation with the appropriate isolate, all plants developed classical symptoms of NFNB, which allowed discrimination of resistant and susceptible genotypes. The distribution of IRs varied among populations (Fig. 1).

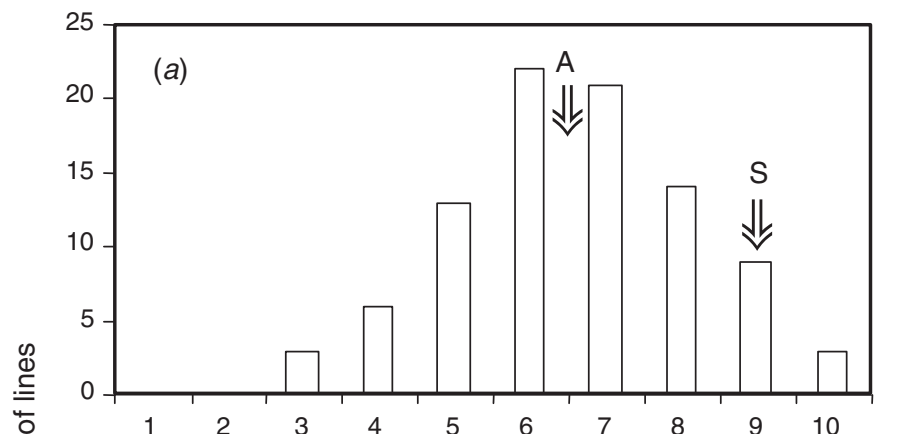

है

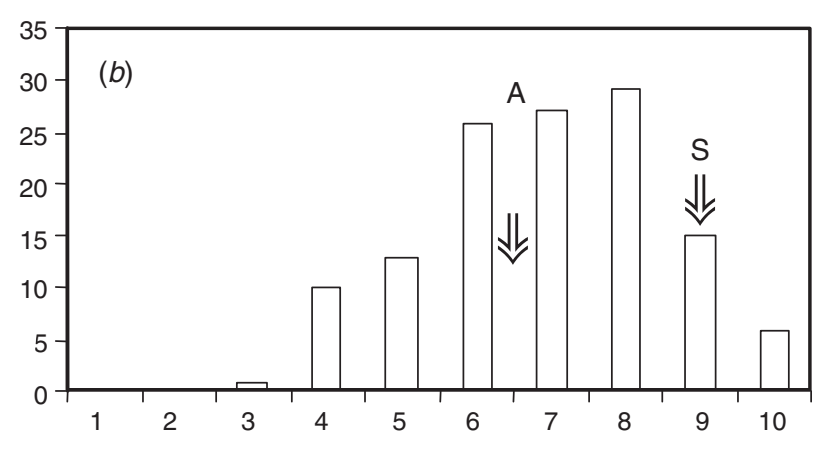

Infection response (1-10)

Fig. 1. Frequency distribution of phenotypes for net form of net blotch resistance in 4 segregating barley populations: $(a)$ Alexis $\times$ Sloop DH population; $(b)$ Sloop-sib $\times$ Alexis RI lines; $(c)$ Arapiles $\times$ Franklin DH population; and $(d)$ Sloop $\times$ Halcyon DH population. Parental means indicated for Alexis (A), Sloop (S), Arapiles (AR), Franklin (F), and Halcyon (H).

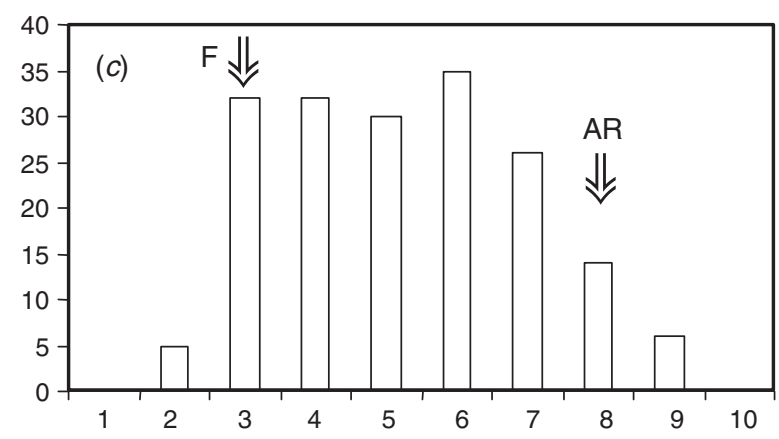

Transgressive segregation for disease response was observed especially in the Alexis/Sloop and Sloop-sib/ Alexis populations (Fig. 1). This indicated that the parents carried different resistance genes.

\section{QTL analyses}

QTL analysis by SIM detected 5 QTLs/genomic regions on $2 \mathrm{H}, 3 \mathrm{H}$, and $4 \mathrm{H}$, contributing $7-64 \%$ phenotypic variance for net blotch resistance (Table 2).

\section{Alexis/Sloop}

In the DH population of Alexis/Sloop, one significant QTL, QRpts3L from Alexis flanked with P14/M61-154 and P13/

Table 1. Seedling infection response of mapping parents to 2 pathotypes of net blotch (scale 1-10 where 1 is resistant and 10 is susceptible)

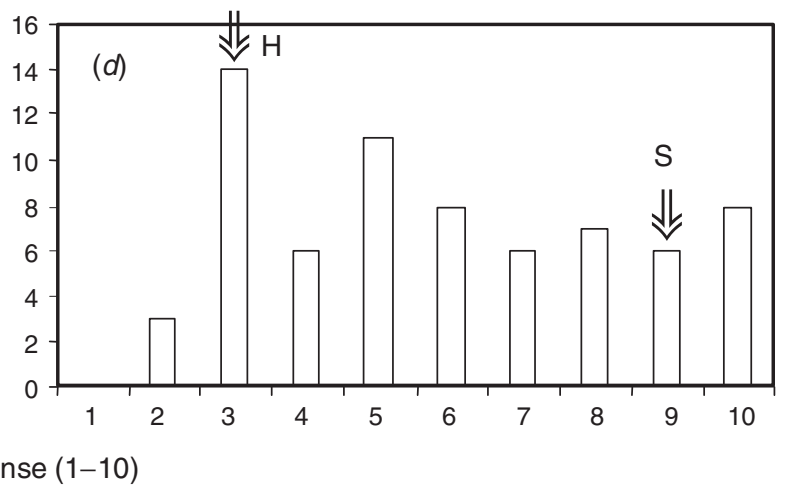

\begin{tabular}{|c|c|c|c|}
\hline \multirow[t]{2}{*}{ Parent } & \multirow[t]{2}{*}{ Isolate } & \multicolumn{2}{|c|}{ Reaction to $P$. teres $\mathrm{f}$. teres } \\
\hline & & Replicate 1 & Replicate 2 \\
\hline Alexis & NB34 & 6 & 7 \\
\hline Sloop & NB34 & 9 & 9 \\
\hline Franklin & NB34 & 3 & 3 \\
\hline Arapiles & NB34 & 7 & 9 \\
\hline Halcyon & NB50 & 3 & 3 \\
\hline Sloop & NB50 & 9 & 9 \\
\hline
\end{tabular}


Table 2. QTLs identified for net form of net blotch resistance from 4 barley populations using simple interval mapping by Map Manager

\begin{tabular}{|c|c|c|c|c|c|c|c|}
\hline \multirow[t]{2}{*}{ QTL } & \multirow[t]{2}{*}{ Marker interval } & \multirow[t]{2}{*}{ Chromosome } & \multirow[t]{2}{*}{ Closest marker ${ }^{\mathrm{A}}$} & \multicolumn{2}{|c|}{ Interval analysis } & \multirow[t]{2}{*}{ Add. effect ${ }^{\mathrm{C}}$} & \multirow{2}{*}{$\begin{array}{c}\lambda^{2} \text { Statistics }^{\mathrm{D}} \\
P<0.05 \\
(P<0.001)\end{array}$} \\
\hline & & & & LRS & $\begin{array}{l}r^{2 \mathrm{~B}} \\
(\%)\end{array}$ & & \\
\hline \multicolumn{8}{|c|}{ Alexis/Sloop-DH } \\
\hline QRpts $2 S$ & $\begin{array}{l}\mathrm{P} 12 / \mathrm{M} 50-241 \\
\mathrm{P} 13 / \mathrm{M} 47-399\end{array}$ & $2 \mathrm{HS}$ & P13/M47-399 & 11.7 & 11 & 0.56 (Sloop) & $12.9(19.7)$ \\
\hline QRpts $3 L$ & $\begin{array}{l}\text { P14/M61-154 } \\
\text { P13/M50-331 }\end{array}$ & $3 \mathrm{HL}$ & $\mathrm{P} 14 / \mathrm{M} 61-154$ & 18.5 & 17 & 0.80 (Alexis) & \\
\hline \multicolumn{8}{|c|}{ Sloop-sib/Alexis-RIL } \\
\hline QRpts $2 S$ & $\begin{array}{l}\text { P14/M48-94 } \\
\text { P12/M50-199 }\end{array}$ & $2 \mathrm{HS}$ & P12/M50-199 & 12.4 & 9 & 0.49 (Sloop) & $12.7(19.2)$ \\
\hline QRpts $3 L$ & $\begin{array}{l}\text { P14/M61-154 } \\
\text { ABG4 }\end{array}$ & $3 \mathrm{HL}$ & P14/M61-154 & 17.4 & 13 & 0.61 (Alexis) & \\
\hline \multicolumn{8}{|c|}{ Arapiles/Franklin-DH } \\
\hline QRpts $2 S$ & $\begin{array}{l}\text { P13/M47-399 } \\
\text { P14/M47-299 }\end{array}$ & $2 \mathrm{HS}$ & P14/M47-299 & 22.9 & 13 & 0.90 (Franklin) & $12.6(20.9)$ \\
\hline QRpts $2 L$ & P11/M62-160 & $2 \mathrm{HL}$ & P11/M62-160 & 12.5 & 7 & 0.46 (Franklin) & \\
\hline QRpts3La & $\begin{array}{l}\text { P11/M62-261 } \\
\text { Bmag0225 }\end{array}$ & $3 \mathrm{HL}$ & P13/M62-299 & 28.7 & 16 & 0.69 (Arapiles) & \\
\hline QRpts $3 L b$ & $\begin{array}{l}\text { P11/M62-212 } \\
\text { P13/M48-312 }\end{array}$ & $3 \mathrm{HL}$ & P13/M60-185 & 16.3 & 9 & 0.52 (Franklin) & \\
\hline \multicolumn{8}{|c|}{ Sloop/Halcyon-DH } \\
\hline QRpts4 & $\begin{array}{l}\text { P11/M48-105 } \\
\text { ABG472 }\end{array}$ & $4 \mathrm{H}$ & P13/M50-108 & 94.4 & 64 & 2.03 (Halcyon) & $13.0(24.7)$ \\
\hline QRpts6L & WG0622-2 & $6 \mathrm{HL}$ & WG0622-2 & 10.3 & 11 & 0.85 (Halcyon) & \\
\hline
\end{tabular}

${ }^{\mathrm{A}}$ Markers detecting maximum LRS (likelihood ratio statistics).

${ }^{\mathrm{B}} r^{2}$, total trait variance explained by a QTL.

${ }^{\mathrm{C}}$ Additive regression coefficient for the association. Name given in parentheses is the parent contributing the favourable allele.

${ }^{\mathrm{D}}$ The threshold for highly significant $(P<0.01)$ and significant $(P<0.05)$ associations as determined using permutation tests.

M50-331 (LRS $\left.=18.5, r^{2}=17 \%\right)$, was detected on $3 \mathrm{HL}$ (Table 2, Fig. 2b). However, another non-significant 'weak' QTL from Sloop, reaching close to the level of significance (LRS $=11.7 / \mathrm{LOD}>2.5, r^{2}=11 \%$ ), was identified on $2 \mathrm{HS}$ (Table 2, Fig. 2a).

In the RILs of Sloop-sib/Alexis, a similar QTL, QRpts $3 L$ flanked with P14/M61-154 and ABG4, was detected on 3HL (Fig. 2d). The AFLP locus XP14/M61-154 detected maximum variability (LRS $=17.4, r^{2}=13 \%$ ) as revealed by bootstrap analysis (Table 2). SIM indicated that QRpts3L from Alexis increased the phenotypic variation for resistance to NFNB. Another non-significant weak QTL approaching the level of significance (LRS $=12.4, r^{2}=9 \%$ ) was also detected with MMQTX on 2HS in RILs of Sloop-sib/Alexis (Table 2). This weak QTL-QRpts2Sa in Fig. 2c-was significant, attaining an LOD score of $>3.0$, when interval mapping was carried out with QGene. This software also detected a genomic region, designated as QRpt $2 s b$, which had an LOD score of 3.0 (Fig. 2c).

\section{Arapiles/Franklin}

SIM and CIM showed evidence for a total of 4 QTLs affecting NFNB resistance in the DH population of Arapiles/
Franklin. One highly significant QTL, designated as QRpts2S, from Franklin, was flanked with P13/M47-399 and co-segregating markers P14/M47-299 and P14/M48-332 $\left(\mathrm{LRS}=22.9, r^{2}=13 \%\right)$ on $2 \mathrm{HS}$. A second QTL, QRpts $2 L$, nearing the level of significance $(\mathrm{LRS}=12.5 / \mathrm{LOD}=2.7$ ) and explaining $7 \%$ of the phenotypic variance, was detected at XP11/M62-160 on 2HL (Table 2). A third highly significant QTL, QRpts3La, flanked with P11/M62-261 and Bmag0225 markers (LRS $=28.7, r^{2}=16 \%$ ), from Arapiles, and a fourth significant QTL (QRpts3Lb) with marker intervals of P11/M62-212 and P13/M48-312 detecting 9\% of phenotypic variance, were identified on $3 \mathrm{HL}$ (Table 2). At 3 of the 4 QTLs linked with NFNB resistance, alleles from Franklin were in the direction of increasing resistance, and an allele from Arapiles at the QRpts 3 La locus increased resistance to isolate NB34. Similar QTLs were detected using the QTL Cartographer program.

\section{Sloop/Halcyon}

A major gene locus, QRpts $4 L$ from Halcyon, flanked by P11/ M48-105 and ABG472 on chromosome 4H, exhibited significant association with NFNB resistance to isolate NB50 (Fig. 3). The P13/M50-108 marker revealed 
(a)

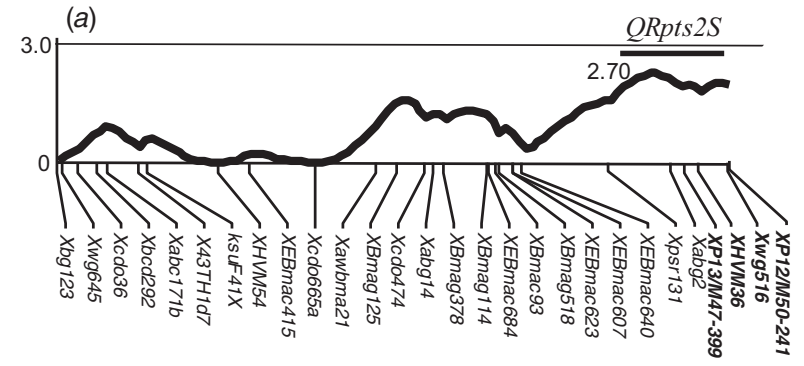

(b)

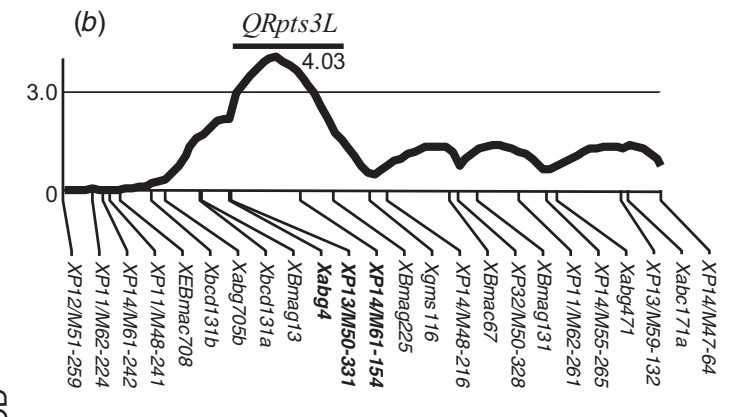

○

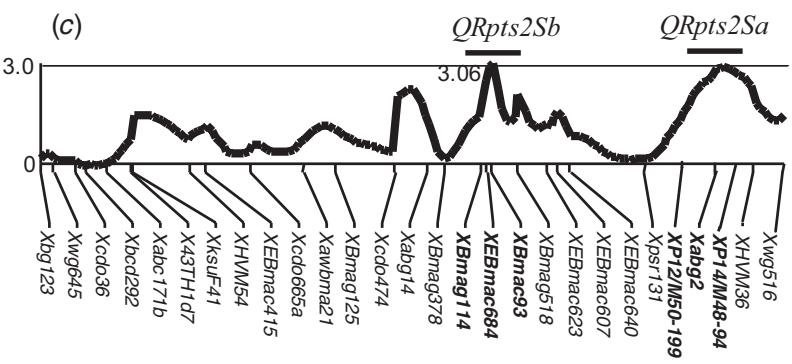

(d)

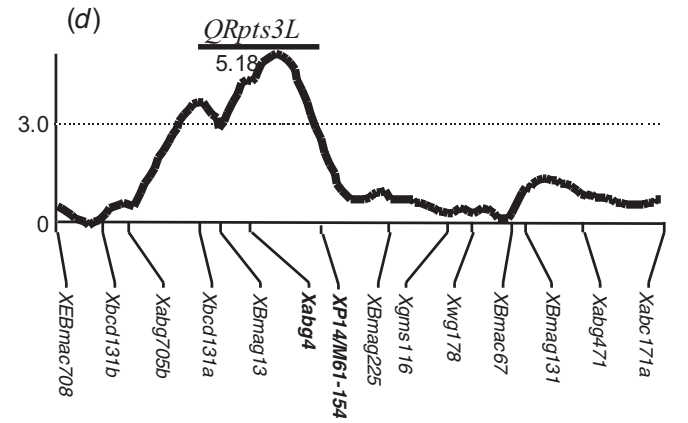

Fig. 2. Map location of QTL associated with net form of net blotch resistance identified using QGENE. Region at or above the threshold LOD score (3.0) shows significant association. (a) QRpts $2 S$ on chromosome $2 \mathrm{H}$ in Alexis $\times$ Sloop DH population; (b) QRpts $3 L$ on chromosome $3 \mathrm{H}$ in Alexis $\times$ Sloop DH population; (c) QRpts $2 \mathrm{Sa}$ and QRpts $2 S b$ on $2 \mathrm{HS}$ in RILs of Sloop-sib $\times$ Alexis; $(d)$ QRpts $3 L$ on chromosome $3 \mathrm{H}$ in RILs of Sloop-sib $\times$ Alexis. Note that for clarity, marker density has been reduced. The actual LOD score of QRpts $2 \mathrm{Sa}$ was 5.19 .

maximum LRS (94.4) as detected by bootstrap analyses and accounted for $64 \%$ of the total variation of net blotch resistance (Table 2).

Similar results were found with simple regression analysis using QTL Cartographer. The AFLP marker P13/

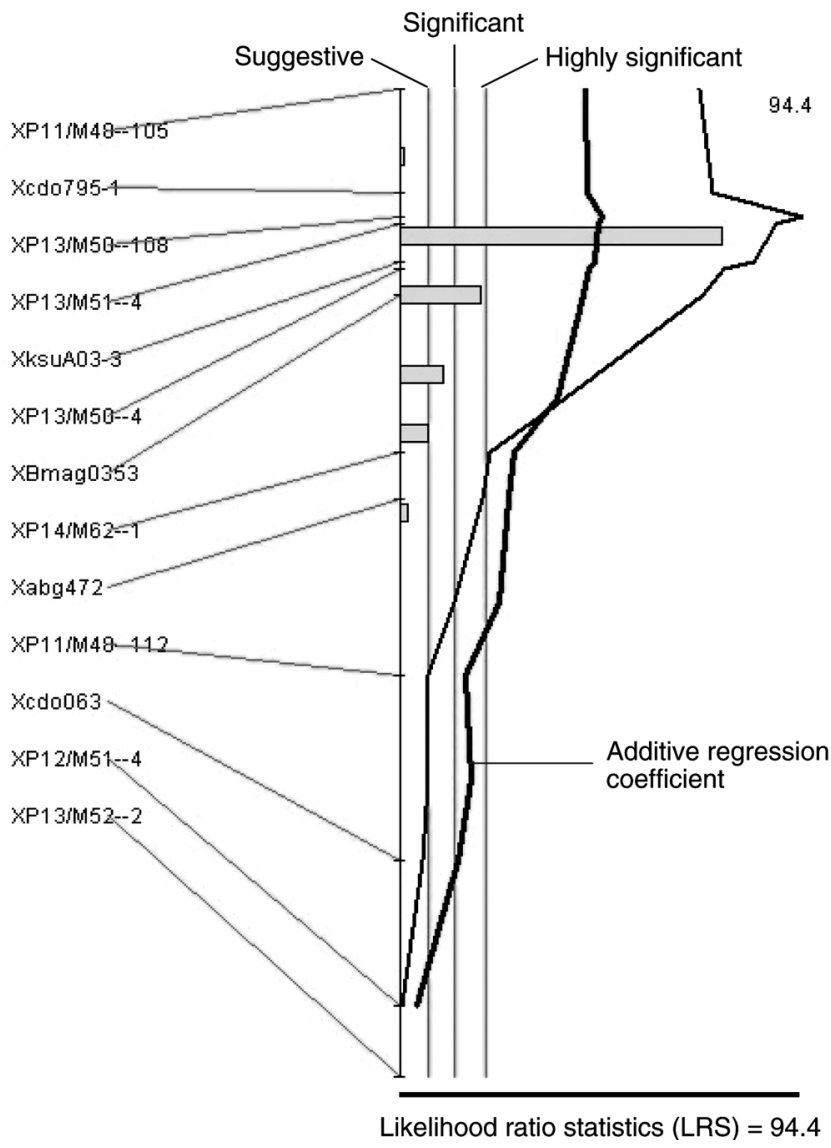

Fig. 3. A major gene associated with net form of net blotch resistance in Sloop $\times$ Halcyon $\mathrm{DH}$ population on chromosome $4 \mathrm{H}$, detected with SIM using MMQTX. The thresholds for highly significant $(P<0.001=\mathrm{LRS}>24.7)$, significant $(P<0.05=\mathrm{LRS}>$ 13.0), and suggestive $(P=0.63)$ as determined using permutation tests are indicated. The histogram indicates the output from bootstrap analysis showing maximum LRS within an identified genomic region, QRpts4L.

M50-108 co-segregated with P14/M16-154, P13/M51-4, and microsatellite markers EBmac0906 and GMS089. These mapped in a cluster in the Sloop/Halcyon DH population (Read et al. 2003). A weak QTL peak on locus Xwg0622b, syn. 'Xwg0622-2', on 6HL approached close to the level of significance $(\mathrm{LRS}=10.3$ ) and explained $11 \%$ of the phenotypic variation, but was not statistically significant (Table 2). The Halcyon allele at this locus conferred NFNB resistance. Two-locus analysis showed non-significant interactions.

\section{Validation of 'QRpts4'}

Results of the validation experiment comprising 81 plants of an $\mathrm{F}_{2}$ population derived from Ant29/Halcyon showed that microsatellite markers EBmac0906 and Bmac0181 may be used for marker assisted selection. The primer sequences of these microsatellite markers were: 


\section{Bmac0181F: 5'-ATAGATCACCAAGTGAACCAC-3' Bmac0181R: 5'-GGTTATCACTGAGGCAAATAC-3' \\ EBmac0906F: 5'-CAAATCAATCAAGAGGCC-3' EBmac0906R: 5'-TTTGAAGTGAGACATTTCCA-3'}

Both the markers EBmac0906 and Bmac0181 cosegregated co-dominantly in $F_{2}$ progeny of the Ant29/ Halcyon population. Chi-square analysis indicated that these segregation ratios $(20: 43: 18)$ fit a single gene model. Resistant and susceptible phenotypes could be correlated with $93 \%$ reliability with the respective marker allele associated with resistance/susceptibility to NFNB. In some cases, resistant and intermediate resistant phenotypes to NFNB could not be correlated with the expected marker alleles. $F_{3}$ progeny testing is being performed to confirm the genotypes of $\mathrm{F}_{2}$ families. Other markers, such as Bmac0310 and Bmag0353 that mapped within 5-10 cM of EBmac0906 in a DH population of Canada Park/Lina (Ramsay et al. 2000; Raman et al. 2003), were also polymorphic in the $\mathrm{F}_{2}$ population of Ant29/Halcyon.

\section{Discussion}

QTL mapping, utilising molecular linkage maps, has proven to be a useful tool for locating major and minor genes, and investigating the parental origins of the favourable QTL alleles controlling genetic variation for NFNB resistance at the seedling stage. In this study, significant putative QTLs for NFNB resistance were detected on chromosomes $2 \mathrm{H}$, $3 \mathrm{H}$, and $4 \mathrm{H}$ in 4 barley populations derived from Alexis/ Sloop, Sloop-sib/Alexis, Arapiles/Franklin, and Sloop/ Halcyon. Several qualitative and quantitative genes conferring net blotch resistance at the seedling stage have been previously reported on $1 \mathrm{H}, 2 \mathrm{H}, 3 \mathrm{H}, 4 \mathrm{H}, 6 \mathrm{H}$, and $7 \mathrm{H}$. Major genes for net blotch resistance in barley, Pt.d/Rpt3.d on chromosome 2H (Bockelman et al. 1977; A. Graner and A. Tekauz, unpublished data) and Pt1 syn. Pt.a/ Rpt1 and Rpt $2 \mathrm{c}$ on chromosome $3 \mathrm{H}$, have been reported (Schaller 1955; Mode and Schaller 1958; Khan and Boyd 1969a; Bockelman et al. 1977; Wilcoxson et al. 1992; Graner et al. 1996). On chromosome 2HS, a QTL for resistance to net blotch of adult plants has been described (Pecchioni et al. 1996; Steffenson et al. 1996). Other qualitative genes for disease resistance including $R y d 2$ for resistance to barley yellow dwarf virus (Collins et al. 1996), Rhy, Rh, and Rrs for scald resistance (Graner and Tekauz 1996; Graner et al. 2000; Genger et al. 2003, this issue), and rym 4, rym5, and rym 11 for virus resistance to strains of $B a M M V$ and $B a Y M V$ (Graner and Bauer 1993; Bauer et al. 1997; Graner et al. 1999), also mapped close to Pt.a/Pt.1 gene for net blotch resistance on the proximal region of $3 \mathrm{HL}$. On chromosome $4 \mathrm{H}$, a large region of the genetic map of Sloop/Halcyon covering $\sim 50 \mathrm{cM}$ exhibited significant association with NFNB resistance (Fig. 4). In this region, several genes such as $M l-g$ and $m l-o$ for resistance to Blumeria graminis f. sp. hordei (Görg et al. 1993), QTLs for quantitative resistance to Puccinia striiformis f. sp. hordei and net blotch in both seedling and adult plant stages, were identified (Hinze et al. 1991; Chen et al. 1994; Steffenson et al. 1996; Manninen et al. 2000). Interestingly, in both the populations derived from Alexis and Sloop (DH/RILs) and Arapiles/Franklin, the same genomic regions of linkage map/QTLs were detected on $2 \mathrm{H}$ and $3 \mathrm{H}$ (Table 2, Fig. 4). Alexis and Franklin are both derivatives of Triumph; Sloop and Arapiles both have Proctor and CI3576 in their pedigree and Franklin also has Proctor in its ancestry. Identification of the same genomic regions/loci suggests that there is a possibility of the same genes or gene clusters associated with NFNB resistance. Hence our results corroborated with previous findings that disease resistance regions are conserved on the genome (Graner et al. 2000). Furthermore, investigations using genetic and molecular analyses have shown that resistance genes and their analogues/homologues are also clustered in genomes of different species (Parniske et al. 1997; Meyers et al. 1998).

All of the QTLs identified in Alexis/Sloop, Sloop-sib/ Alexis, Arapiles/Franklin, and Sloop/Halcyon, occurred at 5 genomic regions that correlated with previously identified major genes/QTLs conferring net blotch resistance. In Fig. 4, the estimated locations of the 'putative' QTLs identified for NFNB resistance in this experiment are compared with those previously reported.

Mean IRs for Alexis and Arapiles differed between these experiments and the initial parent screening (Alexis 6.5 and 4.5, Arapiles 8 and 10, respectively). In the parent screening, inoculum was applied with an airbrush, but as the changes in IRs of the parents were in opposite directions, it is unlikely that this was the reason for disagreement. Inoculum was applied evenly and at the same rate in all experiments so the variation between experiments was most likely a factor of environment. Khan and Boyd (1969b) documented that the resistances of some genotypes were particularly sensitive to environmental influences and it is our experience that this occurs more often with genotypes that are moderately resistant to moderately susceptible, e.g. Alexis.

Isolate NB34 is virulent on the parents Sloop and Arapiles, moderately virulent on Alexis, and avirulent on Franklin. In this study, both Sloop and Arapiles appeared to have a significant QTL on chromosome $2 \mathrm{H}$ and $3 \mathrm{H}$, respectively. The alleles at these loci are obviously inadequate to impart resistance to these varieties in the seedling stage. The QTL on $3 \mathrm{H}$ in Alexis appears to explain the moderate level of resistance in that variety; however, some $25 \%$ of the progeny derived from Alexis and Sloop parents were more resistant than the Alexis parent. It appears that recombination of the allele(s) on $2 \mathrm{H}$ from Sloop with the allele(s) on $3 \mathrm{H}$ from Alexis may have given these lines 


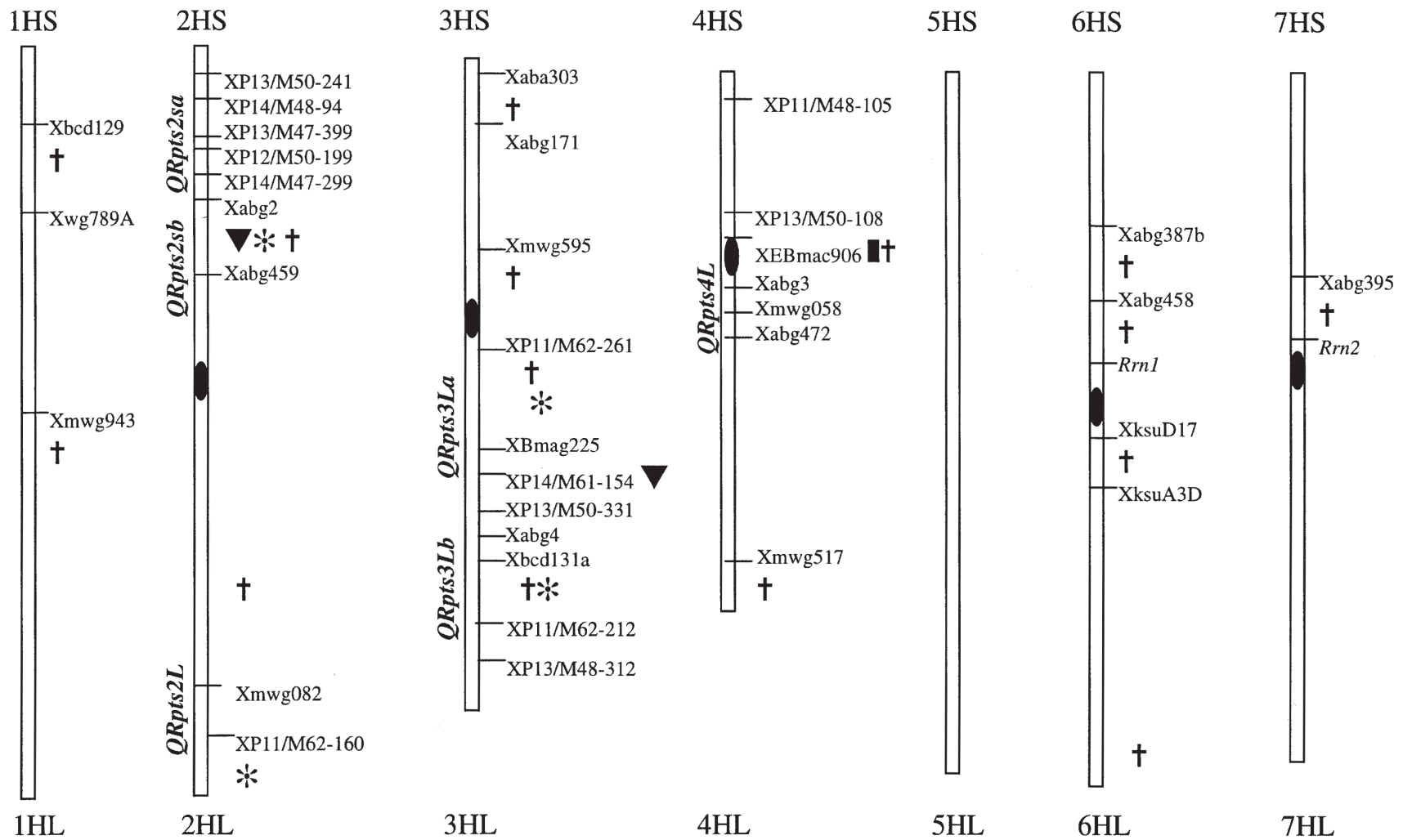

Alexis/Sloop (DH/RILs) Sloop/Halcyon
* Arapiles/Franklin † Previously described

Fig. 4. Barley chromosomes showing mapped chromosome regions associated with net blotch resistance (distances are not marked).

resistance superior to Alexis. Cherif and Harrabi (1993) showed transgressive segregation of progeny of 2 susceptible parents, so it is reasonable to expect that a high proportion of resistant segregants could result from a cross between a moderately susceptible and a susceptible line, each carrying different but complementary genes for resistance.

The resistance in Franklin appears to be conditioned by alleles on chromosomes $2 \mathrm{H}$ and $3 \mathrm{H}$. Franklin is strongly resistant to NB34 isolate of net blotch $(\mathrm{IR}=3)$ and compares with the most resistant progeny of the Alexis/Sloop population. It is suggested that the alleles at these loci have a complementary gene action and can be further enhanced when combined with the relatively ineffective allele on $3 \mathrm{H}$ from Arapiles.

In this study, individual QTLs explained 7-64\% of the phenotypic variation. Some of the QTL regions with an LOD score of $\geq 2.5$ in $\mathrm{DH}$ populations from Alexis/Sloop and Sloop/Halcyon were very close to reaching levels of significance (Table 2). Therefore it is possible that the presence of other 'potential QTLs' that may have had a significant association with the trait, could not be detected due to the specific environments encountered, pathotype used, inoculum density/unit area, relatively small population sizes, and high threshold levels (Beavis 1994). In the present investigation, trait-marker associations were made only at the seedling stage and this may not translate to resistance in the adult plant stages. However, for some resistances, seedling resistance to net blotch is closely correlated with adult plant resistance (Tekauz 1986). Steffenson et al. (1996) found that the QTL on chromosome $4 \mathrm{H}$, presumably the one identified in the Sloop/Halcyon population, functioned in both seedling and adult plants.

Besides determining chromosomal locations, QTL analysis has enabled us to determine genetic control of NFNB by identifying linked genomic regions, thereby eliminating the need to make arbitrary infection classes from frequency distributions. QTL mapping using linkage maps also provided markers that can be used directly for marker assisted selection, as most of the maps used in this study were constructed using both RFLP and microsatellite markers. For example, in the Sloop/Halcyon population, a major QTL explaining 64\% of NFNB resistance is 
associated with microsatellite markers EBmac0906 and GMS089, providing markers suitable for MAS without the need for further manipulation such as conversion into polymerase chain reaction format. RFLP and AFLP markers are costly to implement for routine MAS in breeding programs. On the other hand, microsatellite markers are highly polymorphic, co-dominant, less costly to assay, and are better suited to automation, therefore providing a superior alternative.

Our preliminary results on the validation of molecular markers associated with NFNB have indicated that the linked markers may be used to select loci for NFNB resistance from Halcyon. Furthermore, the microsatellite markers mapped in the QTL region exhibited high polymorphic information content values in Australian and European barley germplasm (Raman et al. 2003), indicating that these markers can be used in different genetic backgrounds. Recently, consensus maps of barley have been developed (Karakousis et al. 2003, this issue) and this will allow further selection of markers mapped closer to the QTLs identified.

From these studies, the information generated on chromosomal location and identification of markers linked to genes conferring resistance to NFNB will allow the Australian barley breeding programs to introgress these genes into adapted germplasm and select lines carrying the favourable alleles using marker assisted selection. Since $P$. teres is a highly variable pathogen (Steffenson and Webster 1992), it is important to combine different QTLs and major genes to develop broad spectrum and high levels of resistance. Genomic regions identified in this study will facilitate in (1) monitoring introgression of pathotypespecific major genes/QTLs and epistatic gene interactions, (2) pyramiding of different genes conferring resistance to $P$. teres, (3) establishing pleiotrophy with other traits, and (4) pedigree-based association mapping.

\section{Acknowledgments}

The authors thank the Grains Research and Development Corporation, Australia, for their financial support, and recognise the valuable technical assistance that made this work possible.

\section{References}

Barr AR, Jefferies SP, Broughton S, Chalmers KJ, Kretschmer JM, Boyd WJR, Collins HM, Roumeliotis S, Logue SJ, Coventry SJ, Moody DB, Read BJ, Poulsen D, Lance RCM, Platz GJ, Park RF, Panozzo JF, Karakousis A, Lim P, Verbyla AP, Eckermann PJ (2003) Mapping and QTL analysis of the barley population Alexis $\times$ Sloop. Australian Journal of Agricultural Research 54, 1117-1123.

Bauer E, Weyen J, Schiemann A, Graner A, Ordon F (1997) Molecular mapping of novel resistance resistance genes against Barley Mild Mosaic Virus (BaMMV). Theoretical and Applied Genetics 95, 1263-1269. doi:10.1007/S001220050691.

Beavis WD (1994) The power and deceit of QTL experiment lessons from comparative QTL studies. In '49th Annual Corn and Sorghum Industry Research Conference'. pp. 250-266. (ASTA: Washington, DC)
Bockelman HE, Sharp EL, Eslick RF (1977) Trisomic analysis of genes for resistance to scald and net blotch in several barley cultivars. Canadian Journal of Botany 55, 2142-2148.

Chen FQ, Prehn D, Hayes PM, Mulrooney D, Corey A, Vivar H (1994) Mapping genes for resistance to barley stripe rust (Puccinia striiformis f.sp. hordei). Theoretical and Applied Genetics 88, 215219.

Cherif M, Harrabi M (1993) Transgressive segregation for resistance to Pyrenophora teres in barley. Plant Pathology 42, 617-621.

Collins NC, Paltridge NG, Ford CM, Symons RH (1996) The $Y d 2$ gene for barley yellow dwarf virus resistance maps close to the centromere on the long arm of barley chromosome 3. Theoretical and Applied Genetics 92, 858-864. doi:10.1007/S001220050203.

Doerge RW, Churchill GA (1996) Permutation tests for multiple loci affecting a quantitative character. Genetics 142, 285-294.

Genger RK, Williams KJ, Raman H, Read BJ, Wallwork H, Burdon JJ, Brown AHD (2003) Leaf scald resistance genes in Hordeum vulgare and Hordeum vulgare ssp. spontaneum: parallels between cultivated and wild barley. Australian Journal of Agricultural Research 54, 1335-1342.

Görg R, Hollricher K, Schulze-Lefert P (1993) Functional analysis and RFLP mediated mapping of the Mlg resistance locus in barley. The Plant Journal 3, 857-866. doi:10.1046/J.1365313X.1993.03060857.X.

Graner A, Bauer E (1993) RFLP mapping of the $y m 4$ virus resistance gene in barley. Theoretical and Applied Genetics 86, 689-693.

Graner A, Foroughi-Wehr B, Tekauz A (1996) RFLP mapping of a gene in barley conferring resistance to net blotch (Pyrenophora teres). Euphytica 91, 229-234.

Graner A, Michalek W, Streng S (2000) Molecular mapping of genes conferring resistance to viral and fungal pathogens. Barley Genetics VIII, 45-52.

Graner A, Streng S, Kellermann A, Schiemann A, Bauer E, Waugh R, Pellio B, Ordon F (1999) Molecular mapping and genetic finestructure of the rym 5 locus encoding resistance to different strains of the Barley Yellow Mosaic Virus Complex. Theoretical and Applied Genetics 98, 285-290. doi:10.1007/S001220051070.

Graner A, Tekauz A (1996) RFLP mapping in barley of a dominant gene conferring resistance to scald (Rhynchosporium secalis). Theoretical and Applied Genetics 93, 421-425. doi:10.1007/ S001220050297.

Gupta S, Loughman R, Platz GJ, Lance RCM (2003) Resistance in cultivated barleys to Pyrenophora teres f. teres and prospects of its utilisation in marker identification and breeding. Australian Journal of Agricultural Research 54, 1379-1386.

Haley SD, Knott SA (1992) A simple regression method for mapping quantitative trait loci in line crosses using flanking markers. Heredity 69, 315-324.

Hinze K, Thompson RD, Ritter E, Salamini F, Schulze-Lefert P (1991) Restriction fragment length polymorphism-mediated targeting of the ml-o resistance locus in barley (Hordeum vulgare L.). Proceedings of the National Academy of Sciences of the United States of America 88, 3691-3695.

Jalli M, Robinson J (2000) Stable resistance in barley to Pyrenophora teres f.teres isolates from the Nordic-Baltic region after increase on standard host genotypes. Euphytica 113, 71-77 doi:10.1023/ A: 1003912825455 .

Karakousis A, Gustafson JP, Chalmers KJ, Barr AR, Langridge P (2003) A consensus map of barley integrating SSR, RFLP, and AFLP markers. Australian Journal of Agricultural Research 54, 1173-1185.

Khan TN, Boyd WJR (1969a) Inheritance of resistance to net blotch in barley. II. Genes conditioning resistance against race W.A.-2. Canadian Journal of Genetics and Cytology 11, 592-597. 
Khan TN, Boyd WJR (1969b) Environmentally induced variability in the host reaction of barley to net blotch. Australian Journal of Biological Sciences 22, 1237-1244.

Manly KF, Cudmore RH Jr, Meer JM (2001) Map Manager QTX, crossplatform software for genetic mapping. Mammalian Genome 12 , 930-932. doi:10.1007/S00335-001-1016-3.

Manninen O, Kalender R, Robinson J, Schulman AH (2000) Application of BARE-1 retrotransposon markers to the mapping of a major resistance gene for net blotch in barley. Molecular and General Genetics 264, 325-334. doi:10.1007/S004380000326.

Meyers BC, Chin DB, Shen KA, Sivaramakrishnan S, Lavelle DO, Zhang Z, Michelmore RW (1998) The major resistance gene cluster in lettuce is highly duplicated and spans several megabases. The Plant Cell 10, 1817-1832. doi:10.1105/TPC.10.11.1817.

Mode CJ, Schaller CW (1958) Two additional factors for host resistance to net blotch in barley. Agronomy Journal 50, 15-18.

Nelson JC (1997) QGENE: software for marker based genomic analysis and breeding. Molecular Breeding 3, 239-245. doi:10.1023/ A: 1009604312050 .

Parniske M, Hammond-Kosack KE, Golstein C, Thomas CM, Jones DA, Harrison K, Wulff BBH, Jones JDG (1997) Novel resistance specificities results from sequence exchange between tandemly repeated genes at the $C f-4 / 9$ locus of tomato. Cell 91, 821-832.

Pecchioni N, Faccioli P, Toubia-Rahme H, Vale G, Terzi V (1996) Quantitative resistance to barley leaf stripe (Pyrenophora graminea) is dominated by one major locus. Theoretical and Applied Genetics 93, 97-101. doi:10.1007/S001220050253.

Poulsen DME, Johnston RP, Platz GJ, Fox G, Kelly A, Sturgess JM, Fromm RL, Laufer MJ Inkerman PA Butler D (1999) Effects of foliar diseases on Northern Region grain production in the 1998 winter cropping season. In 'Proceedings of the 9th Australian Barley Technical Symposium'. Melbourne, Australia. pp. 2.20.012.20.05. http://www.regional.org.au/au/abts/1999/poulsen.htm?PH PSESSID=3bfd038b2176fe3721f835f6cfe64379\#TopOfPage.

Raman H, Karakousis A, Moroni JS, Raman R, Read BJ, Garvin DF, Kochian LV, Sorrells ME (2003) Development and allele diversity of microsatellite markers linked to the aluminium tolerance gene Alp in barley. Australian Journal of Agricultural Research 54, 1315-1321.

Raman H, Moroni JS, Sato K, Read BJ, Scott BJ (2002) Identification of AFLP and microsatellite markers linked with an aluminium tolerance gene in barley (Hordeum vulgare L.). Theoretical and Applied Genetics 105, 458-464. doi:10.1007/S00122-002-0934-0.

Raman H, Read BJ (2000) Molecular breeding for resistance to Russian Wheat Aphid in barley. Journal of Agricultural Genomics 5, 1-5. (http://www.cabi-publishing.org/gateways/jag/papers00/paper100/ indexploo.html)

Ramsay L, Macaulay M, degli Ivanissevich S, MacLean K, Cardle L, Fuller J, Edwards KJ, Tuvesson S, Morgante M, Massari A, Maestri E, Marmiroli N, Sjakste T, Ganal M, Powell W, Waugh R (2000) A simple sequence repeat based linkage map of barley. Genetics 156, 1997-2005.

Read BJ, Raman H, McMichael G, Chalmers KJ, Ablett GA, Platz GJ, Raman R, Genger RK, Boyd WJR, Li CD, Grime CR, Park RF, Wallwork H, Prangnell R, Lance RCM (2003) Mapping and QTL analysis of the barley population Sloop $\times$ Halcyon. Australian Journal of Agricultural Research 54, 1145-1153.
Richter K, Schondelmaier J, Jung C (1998) Mapping of quantitative trait loci affecting Drechslera teres resistance in barley with molecular markers. Theoretical and Applied Genetics 97, 12251234. doi:10.1007/S001220051014.

Schaller CW (1955) Inheritance of resistance to net blotch of barley. Phytopathology 45, 174-176.

Shipton WA, Khan TN, Boyd WJR (1973) Net blotch of barley. Review of Plant Pathology 52, 269-290.

Smedegaard-Petersen V (1971) Pyrenophora teres f. maculata f. nov. and Pyrenophora teres f. teres on barley in Denmark. Aarsskr K VetLandbohojsk, 124-144.

Speakman JB, Pommer EH (1986) A simple method for producing large volumes of Pyrenophora teres spore suspension. Bulletin of the British Mycological Society 20, 129.

Steffenson BJ, Hayes PM, Kleinhofs A (1996) Genetics of seedling and adult plant resistance to net botch (Pyrenophora teres $\mathrm{f}$. teres) and spot blotch (Cochliobolus sativus) in barley. Theoretical and Applied Genetics 92, 552-558. doi:10.1007/S001220050162.

Steffenson BJ, Webster RK (1992) Quantitative resistance to Pyrenophora teres f. teres in barley. Phytopathology 82, 407-411.

Tekauz A (1985) A numerical scale to classify reactions of barley to Pyrenophora teres. Canadian Journal of Plant Pathology 7, 181183.

Tekauz A (1986) Effect of plant stage and leaf position on the reaction of barley to Pyrenophora teres. Canadian Journal of Plant Pathology 8, 380-386.

Tekauz A (1990) Characterisation and distribution of pathogenic variation in Pyrenophora teres $\mathrm{f}$. sp teres and P. teres $\mathrm{f}$. sp. maculata from western Canada. Canadian Journal of Plant Pathology 12, $141-148$.

Tekauz A, Buchannon KW (1977) Distribution and sources of resistance to biotypes of Pyrenophora teres in Western Canada. Canadian Journal of Plant Pathology 57, 389-395.

Visscher PM, Thompson R, Haley CS (1996) Confidence intervals in QTL mapping by bootstrapping. Genetics 143, 1013-1020.

Wang S, Basten CJ Zeng Zhao-Bang (2003) Windows QTL cartographer program. http://statgen.ncsu.edu/qtlcart/ WQTLCart.htm.

Wilcoxson RD, Rasmusson DC, Treeful LM, Suganda T (1992) Inheritance of resistance to Pyrenophora teres in Minnesota barley. Plant Disease 76, 367-369.

Wright RJ, Thaxton PM, EI-Zik KM, Paterson AH (1998) D-sub genome bias of $\mathrm{Xcm}$ resistance genes in tetraploid Gossypium (cotton) suggests that polyploid formation has created novel avenues for evolution. Genetics 149, 1987-1996.

Zeng ZB (1994) Precision mapping of quantitative trait loci. Genetics 136, 1457-1468.

Manuscript received 31 January 2003, accepted 1 August 2003 